Organo- and

Biocatalysis

\title{
Organocatalytic Carbocyclizations
}
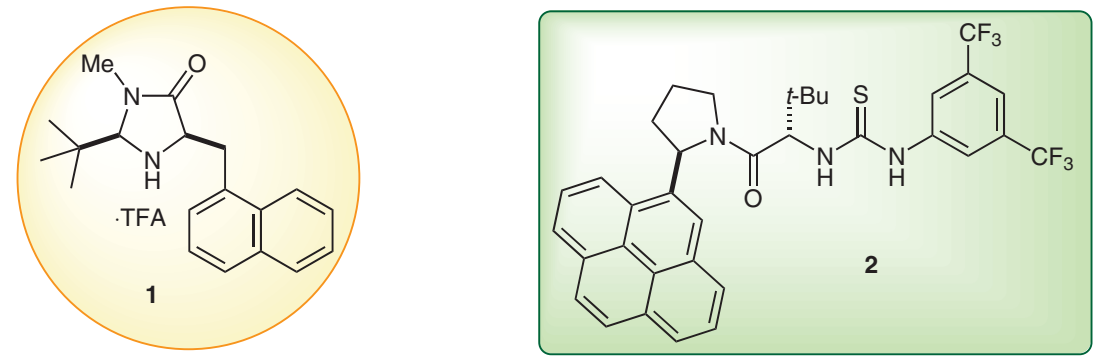

Rendler and MacMillan:<smiles>COc1cc(CCCC(C)=CCCCC=O)cc(OC)c1</smiles>


Knowles, Lin and Jacobsen:
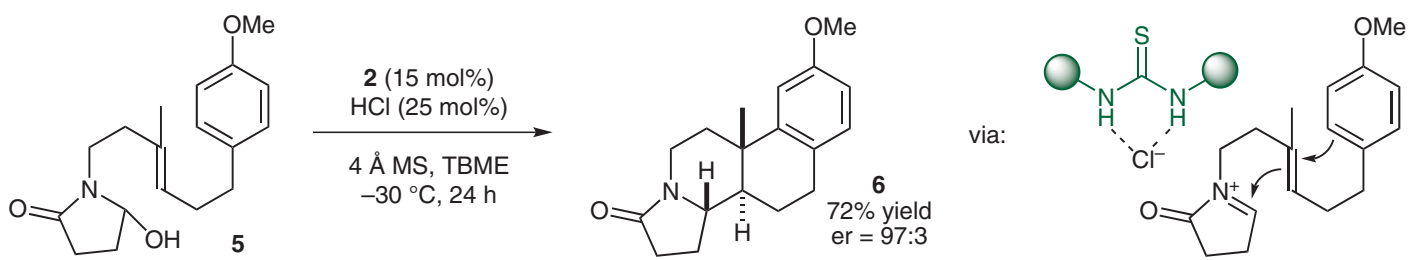

Significance: The research groups of MacMillan and Jacobsen have developed examples of organocatalytic carbocyclizations. Rendler and MacMillan employed organo-SOMO catalysis for cyclizations of polyene aldehydes (e.g., 3).

Polycycles (e.g., 4) were obtained in good yields and enantioselectivity with $30 \mathrm{~mol} \%$ of secondary amine catalyst $\mathbf{1}$. Jacobsen and co-workers developed thiourea catalyst 2 which effects polycyclization of hydroxylactams (e.g., 5). Polycycles (e.g., 6) were obtained in moderate to good yields and enantiomeric ratios up to 97:3.
SYNFACTS Contributors: Benjamin List, Ilija Čorić

Synfacts 2010, 6, 0709-0709 Published online: 20.05.2010 DoI: 10.1055/s-0029-1220005; Reg-No.: B04710SF
Comment: The biosynthesis of complex cyclic terpenes from polyene precursors has inspired the development of biomimetic polyene cyclizations (R. A. Yoder, J. N. Johnston Chem. Rev. 2005, 105, 4730). An enantioselective polyene cyclization induced by Lewis acid assisted chiral Brønsted acid has been developed recently $(H$. Ishibashi, K. Ishihara, H. Yamamoto J. Am. Chem.

Soc. 2004, 126, 11122). The cationic polycyclization reported by Jacobsen is initiated by the formation of a catalyst-bound iminium-chloride ion pair. As the enantioselectivity of the reaction is highly dependent on the size of the arene substituent in 2, stabilizing cation- $\pi$-interactions were proposed. Rendler and MacMillan have accomplished radical polycyclization of polyenals using the previously established organo-SOMO catalysis concept.
Key words

polyene cyclization

cationic polycyclization

organo-SOMO catalysis

thiourea catalysis 